\title{
The London Marathon: 3 years in the
}

\section{running}

\author{
R. CERIO* AND A. MOODY $\dagger$ \\ ${ }^{*}$ Registrar in General Medicine and $\dagger$ House Physician, St Thomas' Hospital, London, \\ England
}

\section{SUMMARY}

Over the 3 years from 1982 to 1984, a total of 34 patients were seen in the Accident and Emergency Department of St Thomas' Hospital, London, as a result of the London Marathon. Clinical details are discussed. Considering the number of annual runners who take part, the casualties from the finish of this event are low. This short report suggests that the 3 years' preparation and organization for the finish of the London Marathon were consistently effective.

\section{INTRODUCTION}

The London Marathon has gained popularity since it was first held in 1980. It is the largest open-entry full marathon $(26.2$ miles or $42 \mathrm{~km})$, with now over 18000 runners. From 1982-1984 the medical area at the finish was situated on Westminster Bridge adjacent to St Thomas' Hospital. This report describes patients taken to the hospital from this event.

Those entering such voluntary pastimes accept the known risks. Superficial trivial injuries are relatively common (Nicholl \& Williams, 1982, 1983), but serious collapse and even death, although they are rare, do occur (Parsons et al., 1984). Consequently, organizers give advice on preparing for the race and describe circumstances that increase the health risks of running. Also first-aid posts and hospitals along the route are provided with a general casualty advice sheet (Tunstall Pedoe, 1984).

\section{METHOD}

Clinical details of runners attending the Accident and Emergency Department of St Thomas' Hospital on the day of the race were classified according to the

Correspondence: Dr R. Cerio, Dermatology Research Registrar, Guy's Hospital, London, SE1 9RT, England 
recommendation made by the consensus conference of the Sports and Health Education Councils (Tunstall Pedoe, 1984).

RESULTS (see Table 1)

The majority of patients had collapsed, but recovered quickly with oral rehydration The need for intravenous fluids was not necessarily an indication for admission although the use of the short-stay ward was particularly useful.

Table 1 London Marathon runners seen at St Thomas' Hospital

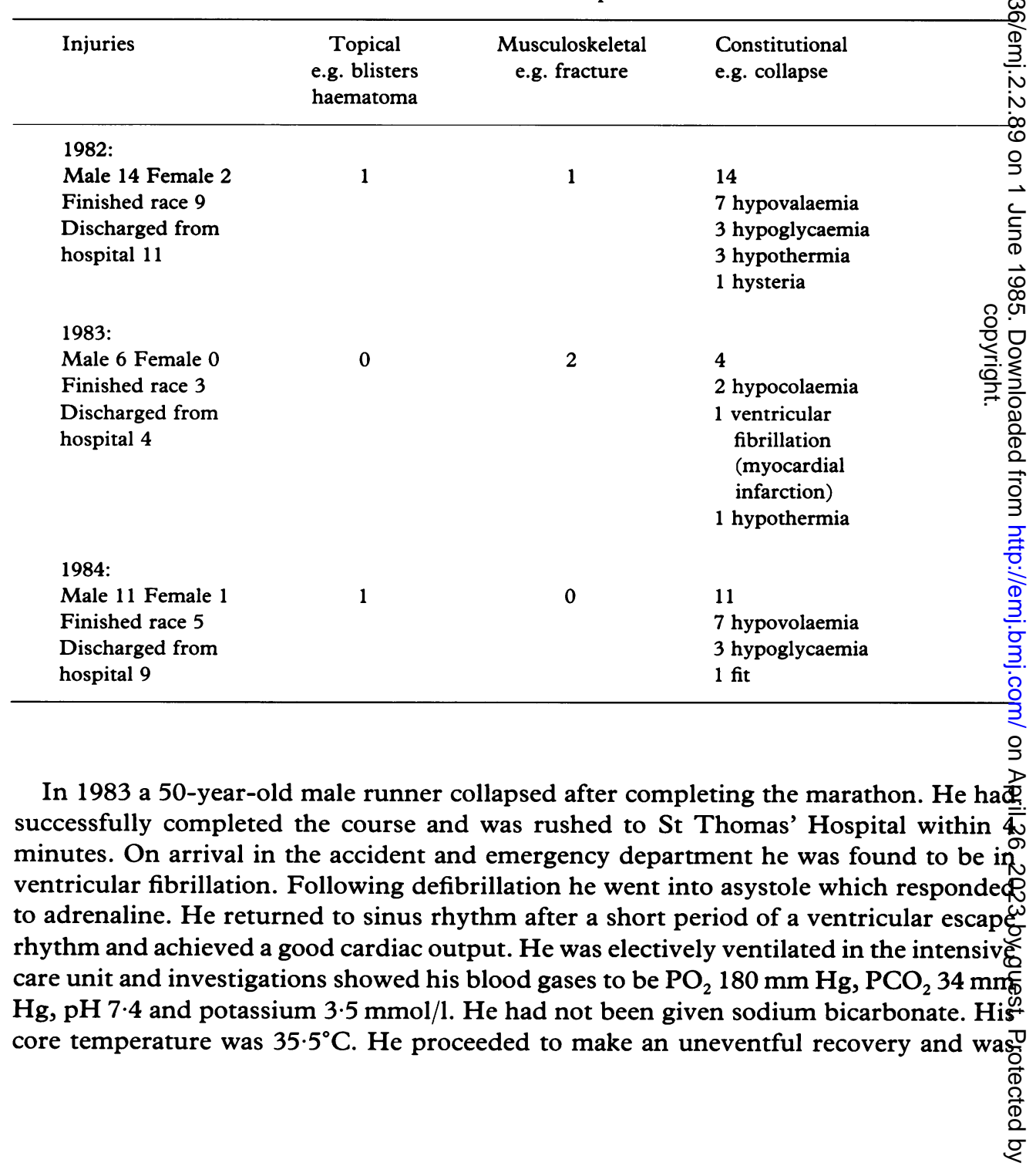


discharged home after 10 days. Serial serum levels of cardiac enzymes and electrocardiograms confirmed a small inferior myocardial infarction.

This year most casualties had collapsed due to hypovolaemia. Three runners were mildly hypoglycaemic, but none was hypo- nor hyperthermic. One epileptic man on treatment had a grand mal fit after crossing the finishing line. Surprisingly, he was given chlorpromazine $25 \mathrm{mg}$ intramuscularly rather than diazepam by the first-aid team; he did not require further medication and recovered fully overnight. The only admission in 1984 was a 21-year-old man who was hypovolaemic and responded poorly to intravenous rehydration.

\section{DISCUSSION}

The experience of medical problems over the 3 years from 1982-1984 as a result of the London Marathon reveals that few casualties have had to be sent to St Thomas' Hospital at the finish of the race. The problems seem to depend on the state of health and preparedness of the runners, on climatic conditions, and on the first-aid arrangements. Williams \& Nicholl (1984) recently reported that the arrangements for preventing and treating medical problems in many marathons were inadequate. Our findings suggest that first-aid medical support at the finish of the London Marathon from 1982-1984 was of a high standard and was applied consistently.

\section{ACKNOWLEDGEMENT}

The authors are grateful to Miss J. Chard, Senior Nurse in Accident and Emergency, St Thomas' Hospital and to Dr R. P. H. Thompson for their help in preparing this paper.

\section{REFERENCES}

Nicholl J. P. \& Williams B. T. (1982) Popular marathons: forecasting casualties. British Medical fournal 285, 1464-5.

Nicholl J. P. \& Williams B. T. (1983) Injuries sustained by runners during a popular marathon. British Fournal of Sports Medicine 17, 10-15.

Parsons M. A., Anderson P. B. \& Williams B. T. (1984) An 'unavoidable' death in a people's marathon. British fournal of Sports Medicine 18, 38-40.

Tunstall Pedoe D. (1984) Marathons, half marathons and long-distance runs: recommendations for medical support. British Medical fournal 285, 1355-9.

Williams B. T. \& Nicholl J. P. (1984) Medical arrangements in 108 open entry British marathons, 1983. Health Trends 16, 68-70.

Received 19 November 1984; accepted for publication 18 fanuary 1985 